\title{
Strategic Research Based on the Construction of Digital Copyright Base
}

\author{
Yu $\operatorname{Ran}^{1, a}$ \\ ${ }^{1}$ Sichuan University of Jinjiang College, Meishan, Sichuan, China \\ a529790415@qq.com

\begin{abstract}
Constructing an open and modern industrial system with global influence and regional driving force is the resonance of global development, and it is also the inevitable trend of my country's economic construction with international and domestic cycles. The innovative development of the copyright industry is particularly important in the context of innovation and industrialization, industrial chain, and supply chain integration. While copyright is the driving force for the sustainable development of national innovation, digital copyright is the inevitable trend of digital development. The construction of a digital copyright base can accelerate the development of the new economy and cultivate new kinetic energy, including the "artificial intelligence" industry, "big data" industry, "5G" industry, "supply chain" industry, and the development of the copyright industry that is closely related to it.
\end{abstract}

Keywords: Digital copyright, digital economy, base construction, robot copyright, countermeasure research

\section{基于数字版权基地建设之策略研究}

\author{
由宇 1 , a
}

1 四川大学锦江学院, 届山, 四川, 中国

a529790415@qq.com

\section{摘要}

构建具有全球影响力和区域带动力的开放型现代化产业体系是全球发展的共鸣, 也是我国经济建设国际国内双 循环的必然趋势。版权产业的创新发展在双创和产业化、产业链、供应链集合的背景下显得尤为重要。而版权 是国家创新持续发展的驱动力, 数字版权是数字化发展的必然趋势。数字版权基地的建设可以加快发展新经济 培育新动能，包含 “人工智能” 产业、“大数据”产业、“ $5 G$ ” 产业、“供应链”产业，以及于此密切相关的 版权产业发展，全方位、多角度支持产业发展。

\section{关键词: 数字版权 数字经济 基地建设 机器人版权 对策研究}

\section{1. 前言}

全球首个由多国领导人共同签署的数字经济政 策文件《G20 数字经济发展与合作倡议》，标志着数 字经济作为一致行动战略的国际认可度越来越高。数 字经济正在推动新一轮科技革命和产业变革, 以及经 济社会结构的全方位变迁。党的十九大指出, 加快建 设网络强国、数字中国、智慧社会, 大力推进互联网、
大数据、人工智能和实体经济深度融合。世界经济论 坛评估表明，数字化程度每提高 $10 \%$ ，人均 GDP 增长 $0.5 \%-0.62 \%$ ，数字技术驱动高质量发展是中国经济 新旧动能转换的重大历史机遇。与版权产业相关的新 闻出版业、广播影视业、文化演艺业、软件业、动漫 游戏业等产业的数字化在全国都呈几何式增长态势, 尤其以技术及互联网产业集群著称的地区，其隐形价 值不可估量。 


\section{2. 建立数字版权基地的依托条件}

坊间经常有这样一个说辞，未来的发展不在线 上, 也不在线下, 在链上。区块链的应用覆盖了金融、 能源、医疗、网络安全、数字版权等诸多领域, 其中, 区块链技术与数字版权结合的探索、实践以及应用已 经取得了比较明显的成果。区块链以其特有的无法篡 改、非对称加密、智能合约等技术优势为互联网时代 的版权保护与发展困境提供新的契机。区块链技术特 征恰恰为数字版权交易打造了安全高效的交易环境。

目前与数字版权相关的技术有: 版权区块链技 术、DRM 技术、物联网技术、大数据技术、人工智能 技术、云计算等。以及子技术分支的完善及开发, 包 含大数据中的外部数据、内部数据和关键数据预警; AI 技术中的文字、声音、图像中数据归类及关键帧 提取; 物联网中的条码技术、FRID（射频识别技术）、 传感器技术 (声音的抓取采集) 、卫星定位技术 (艺 术品、原稿) 等。这些技术的完善和强化是数字版权 基地建设的先决条件。

建立重大事件的备选方案和预案, 特殊时期的上 报机制和办公体系建设。完善版权评估体系和资产管 理运作; 推进建立版权法庭, 设立中国版权保护中心, 构建快速审查、快速确权、快速维权一体化和行政执 法、审判执行、仲裁协调多渠道的协同保护体系; 版 权交易与投融资基金市场化运作; 版权许可与维权线 上申诉，线上线下快速办理。

\section{3. 具体实施细则规划}

\section{1. 建立快捷高效的版权登记体系}

大力推行 “互联网+政务服务” , 实现部门间数 据共享, 让居民和企业少跑腿、办好事。规范行政行 为、优化办事流程。使人民群众有更平等的机会和更 大的创造空间。版权基地据此应建立 “云上” 版权登 记体系，更便捷高效的完成登记工作。

\section{2. 建立版权区块链联盟}

逐步健全版权产业基础设施。目前已有一些企业 平台进行区块链搭建, 但是每个平台都设立不同的认 证标准, 如果同一份作品上传到不同平台, 则会造成 相互之间认证不兼容的问题。建设 “版权区块链联 盟”, 区块链的版权登记都会伴随着一组 16 进制的 密码, 永久有效且无法篡改, 就像版权的身份证一样 独一无二。且成本低、效率高, 可为海量作品提供版 权存证, 并建立版权交易平台, 利用智能合约实现交 易授权。 ${ }^{[1]}$ 建立 “版权数据库”, 不仅录入新数据, 也推进原有数据库的并入, 将传统文化、非遗等一并 入库。

\section{3 健全版权服务体系}

数字版权基地应在国家版权交易中心基础上创 建专属的信息技术服务中心和版权确权服务平台, 形 成整合服务体系，把确权登记、版权数据信息服务、 版权资产管理及交易有机融合。并在国家版权创新发 展基地建立国际版权交易中心, 实现 “文化输出”, 真正做到文化自信。

\section{4 开发精品 IP 及运营产业链}

以成都为例, 蜀地文化绵长久远、神秘而灿烂, 三国文化、杜普文化、熊猫文化、都江堰文化每个都 享誉盛名。内涵丰富的天府文化, 也孕育出了蜀绣、 蜀锦、瓷胎竹编、川剧变脸等一大批非遗瑰宝。成都 并不缺少文化资源, 却缺少 IP。开发运作成都 IP, 进入全国, 走向世界。由熊猫文化形成特色版权, 变 身区域品牌, 进入文创产业体系, 形成产业链循环。

\section{5. 建立全国数字版权授权中心}

数字经济与实体经济的深度融合成为促进实体 经济振兴与产业转型升级的新动能, 其动力主要源 于数字新技术作用下的产业链组织分工边界拓展、交 易成本降低、价值分配转移、需求变化倒逼四个方 面。在数字化转型的大背景下, 版权数字化成核心议 题。数字经济发展已是时代的需求, 要顺应 “互联网 +” 发展潮流, 积极培育壮大云计算、物联网、智能 终端等新兴信息技术产业, 并向各行各业广泛渗透, 不断催生新产业新业态新模式, 加快传统产业向数字 化、智能化、绿色化转型。

2019 年 12 月在成都国家数字版权交易博览会 上, 以区块链技术为核心的 “斑马” 数字版权服务平 台上线, 为内容产业各类从业者和机构提供数字版权 内容的作品登记、版权认证、价值评估、版权交易、 版权监测、版权保护等全产业链功能。聚焦创造、运 用、保护核心环节，推动版权与互联网、大数据、人 工智能、实体经济深度融合; 健全版权生态服务体系, 出台版权产业政策, 优化版权登记, 拓展公共服务网 络, 推进版权交易中心建设, 引进和培养行业龙头企

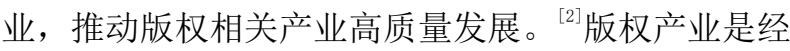
济发展的源动力, 发展数字版权是产业转型升级的重 要拐点, 借助成都现有数字版权发展基础、数据和运 营经验，成就全国数字版权发展。

\section{4. 未来数字版权基地的创新点}

\section{1 政府+行业联盟发展模式}

根据中国新闻出版研究院 “2018 年中国版权产 业经济贡献” 的调研报告, 2018 年中国版权产业的 行业增加值为 6.63 万亿元人民币, 同比增长 $9.0 \%$; 占 GDP 的比重为 $7.37 \%$, 比上年提高 0.02 个百分点。 这个标准在美国的 2009 年就已基本达到。2010 年, 
美国核心版权产业的行业增加值达到 9318 亿元（按 当前汇率为 6.65 万亿人民币), 约占美国整个国民生 产总值（GDP）的 $6.36 \%$ 。同年，整个版权产业的行 业增加值为 16269 亿美元, 占整个美国国民生产总值 的 $11.1 \%$ 。2007 年到 2010 年, 核心版权产业和整个 版权产业所取得的实际年增长率比美国整体经济的 增长率都要高。美国尤其重视知识产权的保护, 美国 与著作权保护有关的机构有很多，包括美国版权局、 美国商务部、美国贸易代表办公室、美国司法部、美 国国土安全部、美国国务院、全国知识产权执法协调 委员会、国际知识产权执法协调员、美国国际贸易委 员会。能给我们的借鉴思考在于, 美国加强国民和数 字出版企业的数字版权保护意识的教育与普及, 有较 强的数字版权保护意识。建立全社会多元协同的数字 版权保护体系。从立法保护、司法保护、行政保护、 社会保护到版权主体自我保护等, 数字版权保护的形 式有机统一, 相辅相成, 真正形成了全方位、多元化 的数字版权保护体系和整体保护机制。从行业组织保 护来说, 可以借鉴美国 “政府 + 行业联盟” 的保护 模式, 为数字版权保护提供保障。加强数字版权行业 协会建设, 研究和制定数字版权行业标准和规范, 引 导数字出版行业走向标准化和规范化, 并倡导行业自 律, 形成良好的行业风气。

建立数字版权行业联盟, “政府+行业联盟” 共 谋模式。亦可建立版权联盟链。针对艺术品市场难交 易的现状, 建立文化艺术品展示交易中心。 ${ }^{[3]}$ 建立版 权运营及保护中心、版权产业发展服务中心。形成区 块链、产业链, 数字版权创新发展研究院, 数字版权 行业联盟, 一链一所一联盟三中心发展格局。

\section{2 利用大数据, 建立版权评估体系}

版权价值评估的适用对象有: 计算机软件著作权 价值评估; 影视剧作品著作权价值评估; 网络游戏著 作权价值评估; 动漫作品著作权价值评估; 舞台剧、 话剧等著作权价值评估; 其他无形资产价值评估。评 估体系分为内核价值评估、外延价值评估、外部监管 三个部分。内核价值评估又下设为: 产品价值观、相 关产品市场占有率, 成熟情况、版权鉴定与创新性等。 外延价值评估包括: 所属行业情况、市场定位、可预 测的消费能力、用户忠诚度、社会影响等。并且注重 行业协会的外部监管, 版权评估体系可随时进行修正 或重新评估。

\section{3 创建机器人版权协会, 人工智能与版权产 业相互促进}

机器人的人工智能创作目前已广泛存在于视 频、音乐、小说、新闻、绘画等领域。 ${ }^{[4]} 2018$ 年阿里 巴巴用户体验设计论坛上, 内部捊化两年的阿里设计 机器人鲁班更名为 “鹿班” , 并首度开始向外输送服 务能力; 同时, 阿里还诞生了首款 “懂感情” 的视频 生成机器人 Aliwood。2017 年双十一鲁班平均每秒能
设计出 8000 张海报, 总量达到 4.1 亿张。2018 年的 鹿班是一个已累计设计了 10 亿次海报的智能设计机 器人。相当于市面上可担纲中等设计项目主创人员的 高级设计师。而设计圈培养出一名高级设计师通常要 花 10 年。 2018 年 1 月上线的 “阿里汉仪智能黑体” 是全球首款中文人工智能字体。该款字体包含 6763 个汉字、682 个非汉字图形字符。人工智能的创作在 国际国内都越来越普遍，而与其相关的版权问题也日 益被提上日程。

文学、艺术等领域的人工智能的作品纳入到版权 保护中, 可激励和促进人工智能的发展并提高人的效 率。但是从反向角度思考, 由于机器人 AI 创作的特 殊性, 钓鱼式营销的情况比较容易实现且成本低。比 如现实中大量存在 “钧鱼式” 字库营销模式, 先将产 品免费推向公众, 之后找到使用字体的企业要求赔 偿。如果任其这样乱象肆意发展, 没有法律制度的健 全、行业公约的约束、宣传政策的出台及人民监督, 其他的人工智能创作也会出现类似的情况, 导致企业 和个人对机器人版权信任度降低, 影响整个行业生 态, 牵累两个潜力产业发展。机器人版权协会, 旨在 从行业角度约束和抵制 “钓鱼式” 营销手段, 对于侵 犯机器人版权行为也辅助积极维权, 促进人工智能与 版权的良性互动, 让人工智能的研发无后顾之忧。

\section{4 推动设立版权法庭, 筹建数字版权法律互 助站}

版权法院是有关版权审判的专门法院，构建快速 审查、快速确权、快速维权一体化和行政执法、审判 执行、仲裁协调的多渠道协同保护体系。本着司法公 开及便民利民的思路，可实施网上立案、网上缴费、 审判流程公开、庭审直播及裁判文书公开。设立立案 庭、审判庭（一庭、二庭、三庭）、审判监督庭等业 务庭。设立技术调查室和司法警察支队 2 个司法辅助 机构, 设立综合办公室作为全院统一的综合行政机 构。

法律互助站采用志愿者服务, 对版权纠纷、版权 维权、版权代理等提供法律服务。建立调解委员会、 法律服务志愿者队伍、法律服务专家团队。

\section{5. 结论}

基于以上实际问题，数字版权基地应计划运营 “数字版权创新发展研究院”, 承担版权基地的发展 规划及相关政策建议、牵头基地招商引资及项目对接 工作、打造版权公共服务平台，为企业提供基础版权 服务。版权资产包含三种状态: 传统的版权资产; 数 字化的版权资产; 量化的版权资产。 ${ }^{[5]}$ 版权资产真正 数字化才可以让版权资产流动起来。并建立数字版权 公链, 符合行业标准的行业公链是发展方向。做到版 权资产上链 (数字证书), 权利信息上链, 作品上链 （作品存证），版权交易的本质就是版权证书的交易， 做到从模糊管理到精确化管理, 构架量化资产。版权 
资源形成版权资产，确权是第一步也是关键，构建版 权云，完成确权服务。和交易所合作构建线上交易中 心或交易平台，明确交易的重要性。

\section{REFERENCES}

[1] YU J.(2020) Research on the Strategy of library digital rights management based on blockchain.J.Wide-angle publishing,03:49-51.

[2] WANG L,DU Y.(2021) Research on the platform mechanism of UGC copyright protection.J.Intellectual Property,08:65-74.

[3] XU C.Y.(2021) On the legal regulation of the exclusive transaction of digital music copyright.J.Intellectual Property,07:50-60.

[4] Chang T.T,Yang X.Y.(2021) Global e-book innovation process and the path of China's rise.J.Library Forum, 10:8.

[5] Yuan J,Zhao J.J.(2021) The Realistic Dilemma and Countermeasures of Digital Copyright Protection in the Era of Big Data.J.Technology and Publishing,07:131-136. 